九州大学学術情報リポジトリ

Kyushu University Institutional Repository

\title{
Acoustic Emission Characteristics in Wood Sanding Amplitude distribution of acoustic emission in disc sanding process
}

Matsumoto, Hiroshi

Laboratory of Wood Technology, Faculty of Agriculture, Kyushu University

Murase, Yasuhide

Laboratory of Wood Technology, Faculty of Agriculture, Kyushu University

https://doi.org/10.5109/24270

出版情報：九州大学大学院農学研究院紀要. 43 (1/2)，pp. 257-268，1998-11. Kyushu University バージョン：

権利関係 : 


\title{
Acoustic Emission Characteristics in Wood Sanding Amplitude distribution of acoustic emission in disc sanding process
}

\author{
Hiroshi Matsumoto and Yasuhide Murase \\ Laboratory of Wood Technology, Faculty of Agriculture, Kyushu University, \\ Fukuoka 812-8581, Japan \\ (Received July 30, 1998 and accepted August 7, 1998)
}

\begin{abstract}
The purpose of this study is to obtain the basic knowledge on acoustic emission (AE) characteristics in wood sanding process.

In sanding parallel and perpendicular to the grain, the $\mathrm{AE}$ event count rate decreased with increasing sanding timte and this tendency was similar to the varialion of stock removal rate with sanding time. The amplitude distribution of $\mathrm{AE}$ signal showed a tendency that the $\mathrm{AE}$ event count rates were greater for lower threshold voltage and they decreased with increasing threshold voltage. Although the AE event count rates were greater in lower threshold voltage for finer grit size, they decrcased with increasing sanding time at each threshold voltage. Both the $\mathrm{AE}$ event count rate and the armplitude distribution of $\mathrm{AE}$ signal in sanding perpendicular to the grain were greater and wider than these values in sanding parallel to the grain, respectively. It was found that the AEs wilh low amplitude were greater for finer grit size and the AEs with high amplitude were greater for coarser grit size. It was suggested that the form of amplitude distribution of $\mathrm{AE}$ signal with sanding time does not change although the $\mathrm{AE}$ event count rate decrease with increasing sanding time.
\end{abstract}

\section{INTRODUCTION}

Recently, $\mathrm{NC}$ and $\mathrm{CNC}$ machines have been developed in the field of wood machining. The monitoring technique of wood machining process is important for the automation of wood machining operations. Acoustic emission refers to the elastic waves (ultrasonic waves) generated by the sudden release of energy in deforming or fracturing materials. Therefore, the wood machining processes such as cutting and sanding all generate acoustic emissions.

In recent years, although the $\mathrm{AE}$ generated during drum sanding process have been investigated (Lemaster and Dornfeld, 1993), only a few investigations on the $\mathrm{AE}$ in wood sanding process have been conducted. So we investigated the effects of grit size, sanding time, sanding pressure and sanding direction on $\mathrm{AE}$ characteristics in belt sanding process (Murase et al., 1995; Matsumoto and Murase, 1997a) and obtained the results as follows. The $\mathrm{AE}$ count rates increase with increases of grit size, and the $\mathrm{AE}$ count rates for each grit size decrease with increasing sanding time. The variations with sanding time in the $\mathrm{AE}$ count rate and the stock removal rate show similar tendencies. For each grit size, the $\mathrm{AE}$ count rates increase with increases of sanding pressure. In sanding perpendicular to the grain, the stock removal rates and the $\mathrm{AE}$ count rates were greater than these values in sanding parallel to the grain. Moreover, we investigated the effects of sanding time, grit size and sanding direction on $\mathrm{AE}$ in disc sanding process (Matsumoto and Murase, 1997b). In sanding parallel and perpendicular to the grain, the stock removal rate decreased with increasing sanding time and the $\mathrm{AE}$ count rate decreased rapidly in 
the initial stage of sanding process. The relationship between the $\mathrm{AE}$ count rate and the grit size in the initial stage of sanding process showed maximum curve. The generation of AE with low amplitude after sanding for 120 minutes were greater for finer grit size.

In this study, to obtain the basic knowledge on AE characteristics in wood sanding process, the $\mathrm{AE}$ generated during sanding process with disc sanding machine were measured, and the effects of sanding time and grit size on both AE and sanding performance (stock removal rate, sanding resistance and roughness of sanded surface) in sanding parallel and perpendicular to the grain were examined.

\section{MATERIALS AND METHODS}

\section{Sanding apparatus and measurement of $\mathrm{AE}$}

The disc sanding apparatus shown in Figure 1 was used in this study. In this apparatus, the specimen was pressed under a constant load on the sanding disc rotating horizontally. The MUSIC system (Multi-analysis System with Intelligent Controller, NF Electronic Instruments) was used for the purpose of measuring $\mathrm{AE}$ signals. This system collects the characteristical data extracted from $1 \mathrm{AE}$ event signal and transmits them to a personal computer. The output signal from the transducer was then amplified by $40 \mathrm{~dB}$ using a preamplifier (NF AE-912). An additional gain of $20 \mathrm{~dB}$ was provided using a main amplifier and then band-pass filtered between $100 \mathrm{kHz}$ and $1 \mathrm{MHz}$ in the MLSIC system. After that, the amplitude distribution of $\mathrm{AE}$ signal whose amplitude are equal to or greater than a given threshold voltage was measured. An AE transducer (NF AE-905U; 1 $\mathrm{MHz}$ resonant frequency) was mounted on the specimen with magnet holder, and silicon grease were used as a couplant between wood specimen and AE transducer.

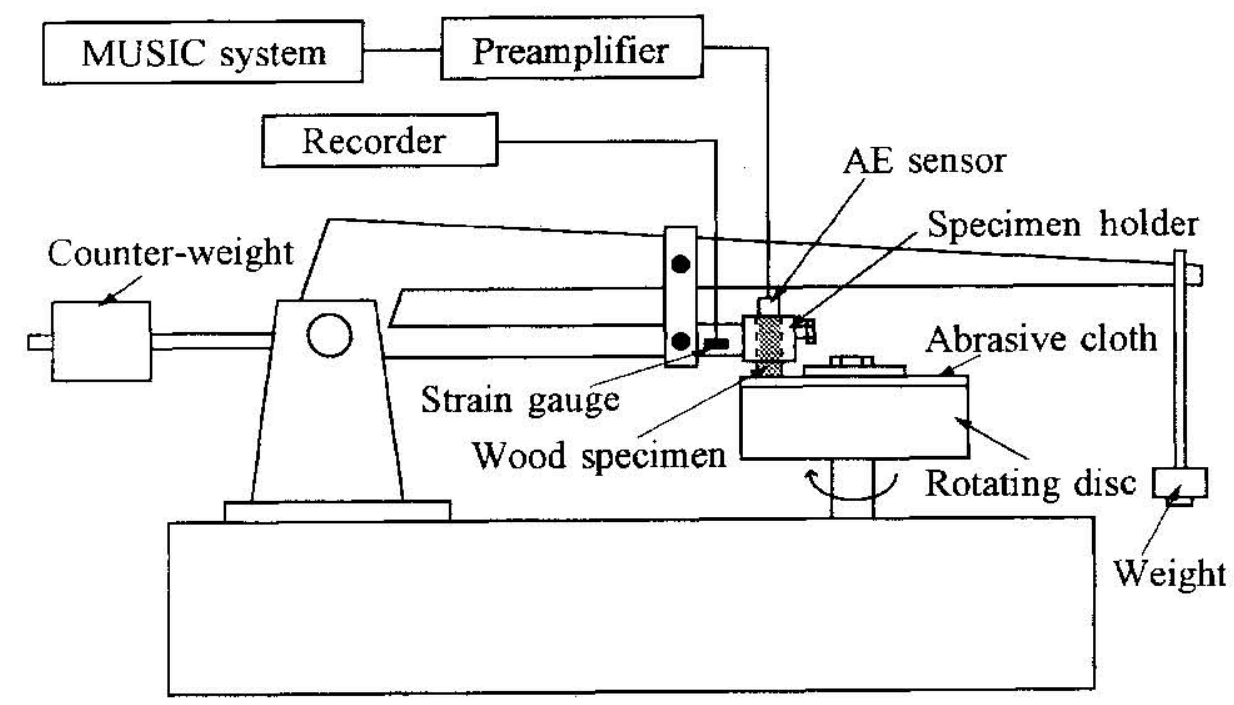

Fig. 1. Configuration of equipment in this study. 


\section{Specimen, abrasive cloth and sanding conditions}

The specimens used were spruce (Picea sp.) with mean specific gravity in air-dried condition of 0.45 and mean moisture content of $11.1 \%$. The dimensions were $15 \mathrm{~mm}$ (Radial direction) $\times 15 \mathrm{~mm}$ (Longitudinal direction) $\times 45 \mathrm{~mm}$ (Tangential direction) Abrasive cloth whose grit sizes of $40,80,150,240$ and 400 were used. The material of abrasive grain was aluminum oxide. The sanding speed and sanding pressure were kept constant at $0.32 \mathrm{~m} / \mathrm{s}$ and $0.55 \mathrm{kgf} / \mathrm{cm}^{2}$, respectively. The sanding on radial face parallel and perpendicular to the grain were conducted for 120 minutes. The stock removal rate was defined as weight change of specimen every $1-10$ minutes. The sanding resistance (the tangential sanding force) was measured by strain gauges on strip-steel spring with specimen holder. The roughness of sanded surface Ry (maximum height: Japanese Industrial Standard: JIS B0601-1994) was measured by using a stylus-type surface roughness measuring instrument (SE1700, Kosaka Laboratory Ltd.), and the trace direction of stylus was perpendicular to the sanding direction.

\section{RESULTS AND DISCUSSION}

\section{Stock removal rate}

Figure 2 shows the variations of the stock removal rates and the ratios of stock removal rate with sanding time for each grit size in sanding parallel and perpendicular to the grain. The ratio of stock removal rate $\left(R^{2} / R_{0}\right)$ is the ratio of stock removal rate at each sanding time $(R)$ to the stock removal rate for initial 1 minute ( $\left.\mathrm{R}_{0}\right)$. The stock removal rate decreased with increasing sanding time. The coarser the grit size the greater the stock removal rate. This is probably due to the increase of the amount of penetration of the abrasive grains to the wood for coarser grit size. The ratio of stock removal rate decreased rapidly in the initial stage of sanding process for finer grit size. This rapid decrease is considered to be affected significantly by the loading of abrasive cloth for finer grit size. Although the stock removal rates in sanding perpendicular to the grain were greater than these values in sanding parallel to the grain for each grit size, the variations with sanding time showed similar tendencies. There was no difference between the ratios of stock removal rate for the two sanding directions.

\section{Sanding resistance}

Figure 3 shows the variations of the sanding resistances with sanding time for each grit size in sanding parallel and perpendicular to the grain. Except for the grit size of 400 , the sanding resistance decreased with increasing sanding time. In the same manner as stock removal rate, the sanding resistances were greater for coarser grit size. The sanding resistance for the grit size of 400 became greater than these values for the grit sizes of 150 and 240 with increasing sanding time. This is probably due to the increase of frictional resistance with increasing contact area between abrasive grain and wood specimen. Although the sanding resistances in sanding perpendicular to the grain were greater than these values in sanding parallel to the grain in the initial stage of sanding process, there seemed to be no difference between the two sanding directions in the last stage of sanding process. This result may be due to the following. That is, since the stock 

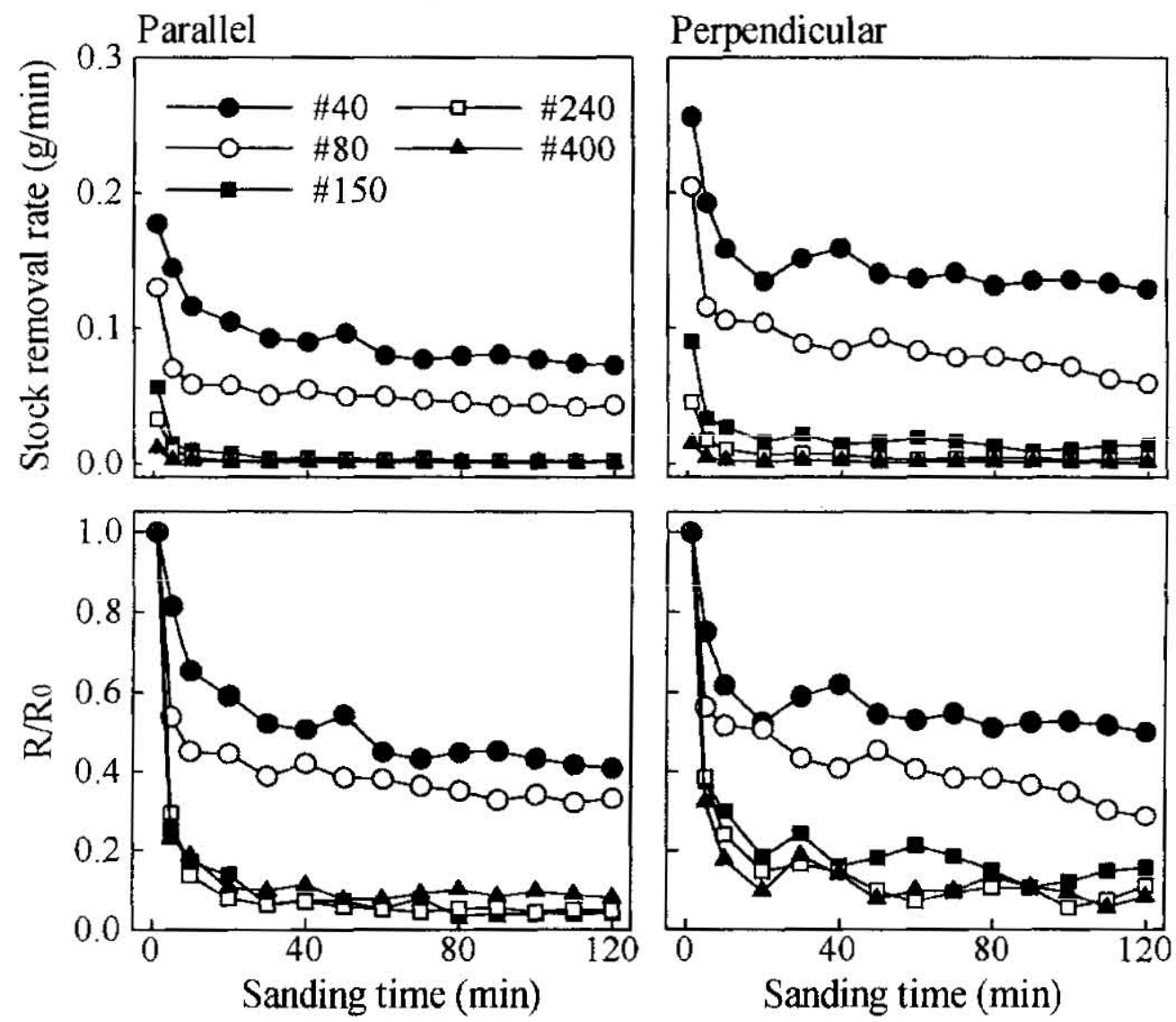

Fig. 2. Variations of stock removal rate and $R / R_{\circ}$ with sanding time for each grit size Legend: R: Stock removal rate for each sanding time, Rı: Stock removal rate for initial 1 minute.

removal rates in sanding perpendicular to the grain are greater than these values in sanding parallel to the grain, both the progress of loading of abrasive cloth and the decrease of the amount of penetration of the abrasive grains to the wood in sanding perpendicular to the grain are faster than these values in sanding parallel to the grain

\section{Roughness of sanded surface}

Figure 4 shows the variations of the roughness of sanded surface Ry with sanding time for cach grit size in sanding parallel and perpendicular to the grain. The roughness decreased for the initial stage of sanding process, and then gradually approached to the constant values for grit sizes of 40 and 80 . The roughness for finer grit size kept constant values with sanding time. These results of the roughness for finer grit size were affected 


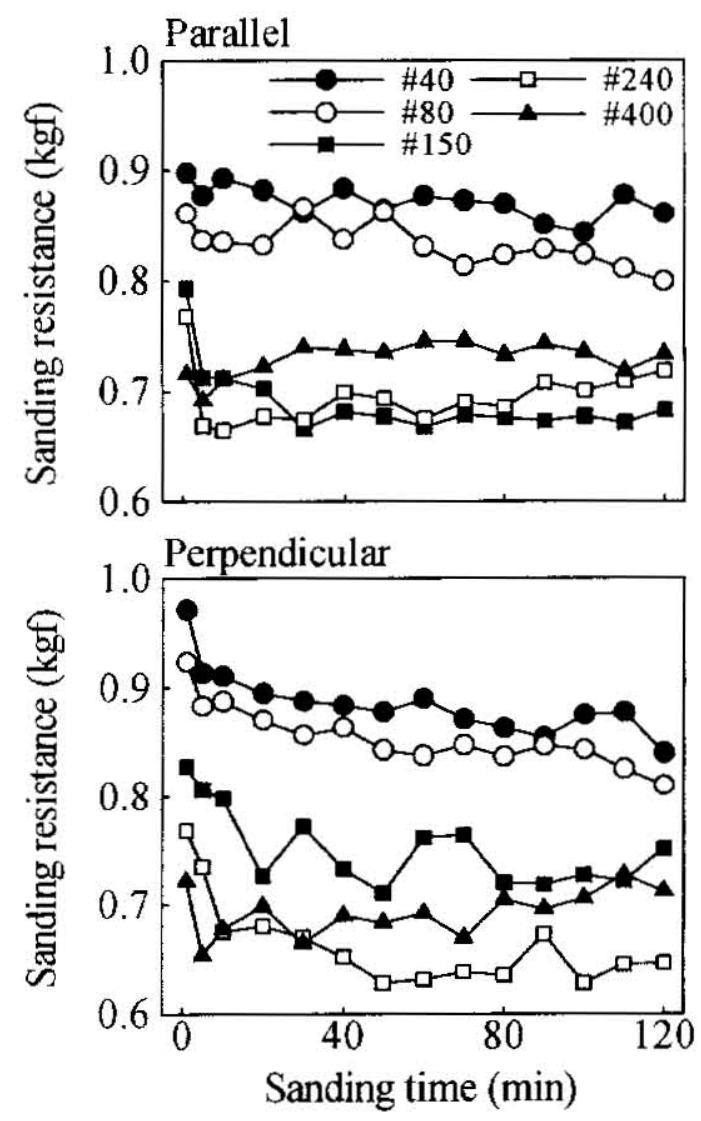

Fig. 3. Variations of sanding resistance with sanding time for each grit size.

by the structure of wood specimen. The roughness in sanding perpendicular to the grain were greater than these values in sanding parallel to the grain for each grit size. These differences in sanding direction may be due to the difference of shape of cutting groove produced during sanding process.

\section{AE measurement}

Discrilevels were decided from the result of preliminary experiment because of capacity of the MUSIC system used in this study. Discrilevels in sanding parallel and perpendicular to the grain were set at $0.3 \mathrm{mV}$ and $0.5 \mathrm{mV}$, respectively. Therefore, the $\mathrm{AE}$ event with high amplitude level in sanding perpendicular to the grain are greater than these values in sanding parallel to the grain. 

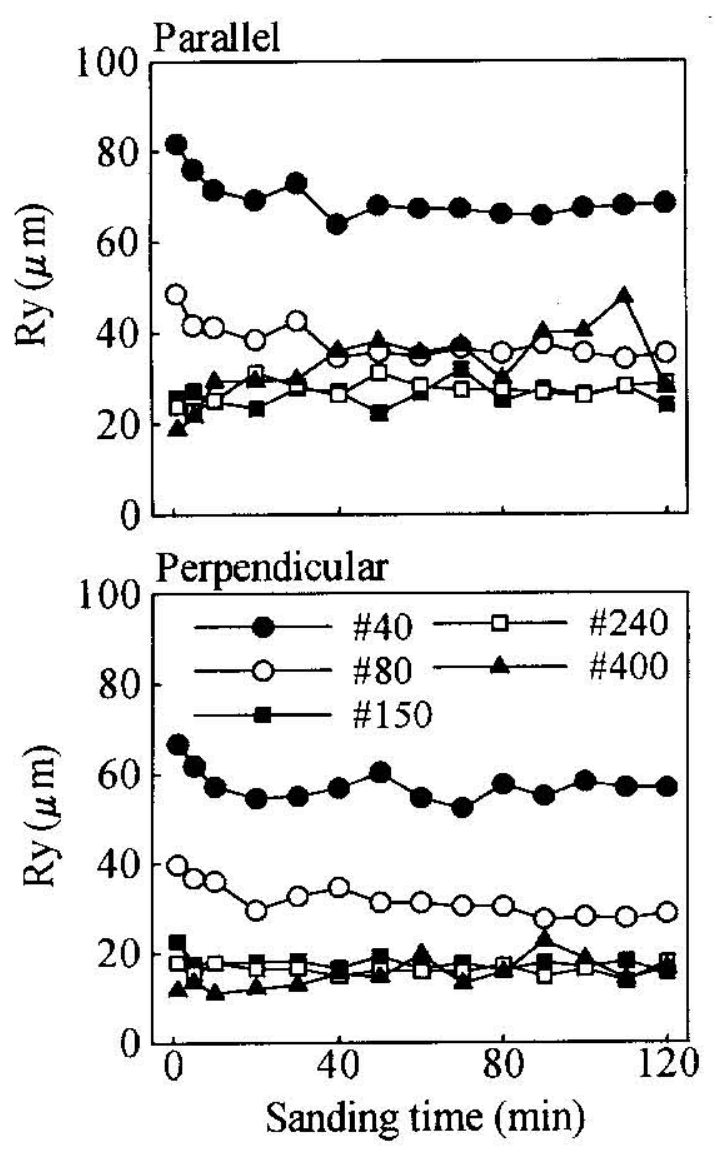

Fig. 4. Variations of Ry with sanding time for each grit size. Legend: Ry: Maximum height of roughness of sanded surface (JIS B0601-1994).

\section{AE event count rate}

Figure 5 shows the variations of the $\mathrm{AE}$ event count rates with sanding time in sanding parallel and perpendicular to the grain. Although there are a scatter, the $\mathrm{AE}$ event count rates decreased with increasing sanding time at each grit size. As pointed out by previous sturdies (Murase et al., 1995; Matsumoto and Murase, 1997a), the decrease of the $\mathrm{AE}$ event count rate with sanding time is considered to be due to the decrease of amount of penetration of the abrasive grains to the wood which was caused by the progress in both the wear of abrasive grain and the loading of abrasive cloth. The finer the grit size the greater the $\mathrm{AE}$ event count rate. The variations of $\mathrm{AE}$ event count rate with sanding time and the dependence of the $\mathrm{AE}$ event count rate on grit size showed similar tendencies in both sanding directions. 


\section{Amplitude distribution of AE signal}

Figures 6 and 7 show the variations of amplitude distributions of AE signal at each grit size in sanding parallel and perpendicular to the grain. The $\mathrm{AE}$ event count rates were greater for lower threshold voltage at each grit size. Although the $\mathrm{AE}$ event count rates were greater in lower threshold voltage for finer grit size, they decreased with increasing sanding time at each threshold voltage. As stated above, although discrilevel was set at $0.5 \mathrm{mV}$ in sanding perpendicular to the grain, the AE event count rates were greater than these values in sanding parallel to the grain. From these results, it was found that both the $\mathrm{AE}$ event count rate and the amplitude distribution of $\mathrm{AE}$ signal in sanding perpendicular to the grain were greater and wider than these values in sanding parallel to the grain, respectively. The decrease of $\mathrm{AE}$ event count rate with increasing sanding time and the dependence of the $\mathrm{AF}$ event count rate on grit size showed similar tendencies in both sanding directions.

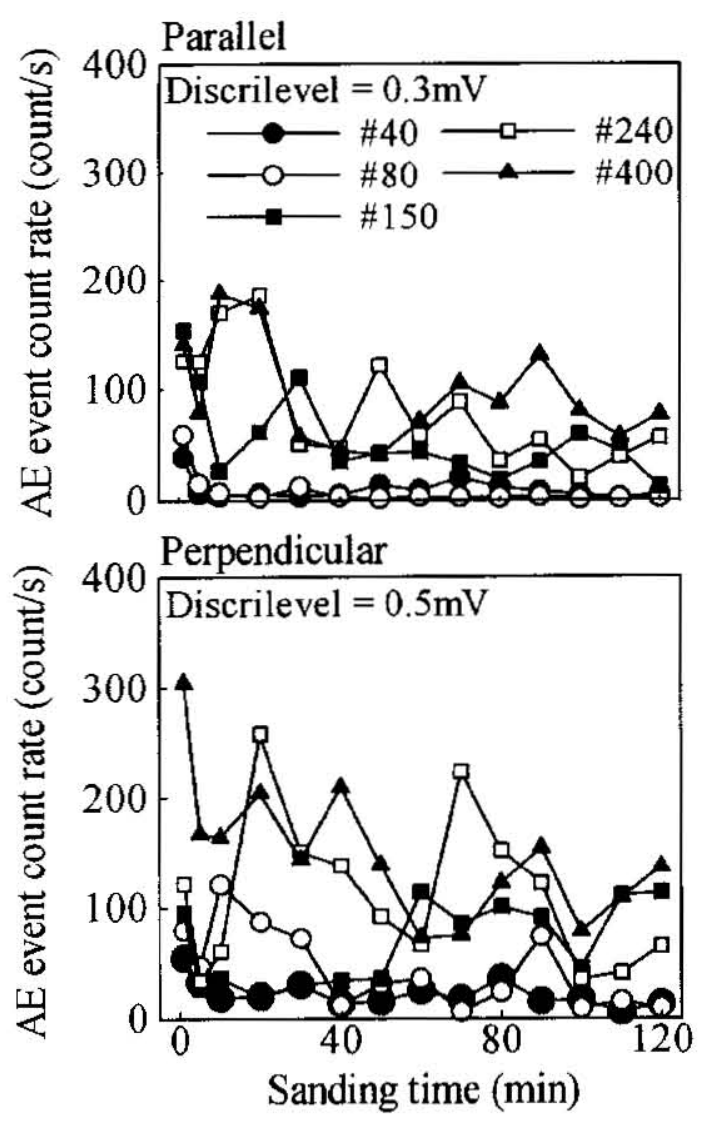

Fig. 5. Variations of AE event count rate with sanding time for each grit size. 

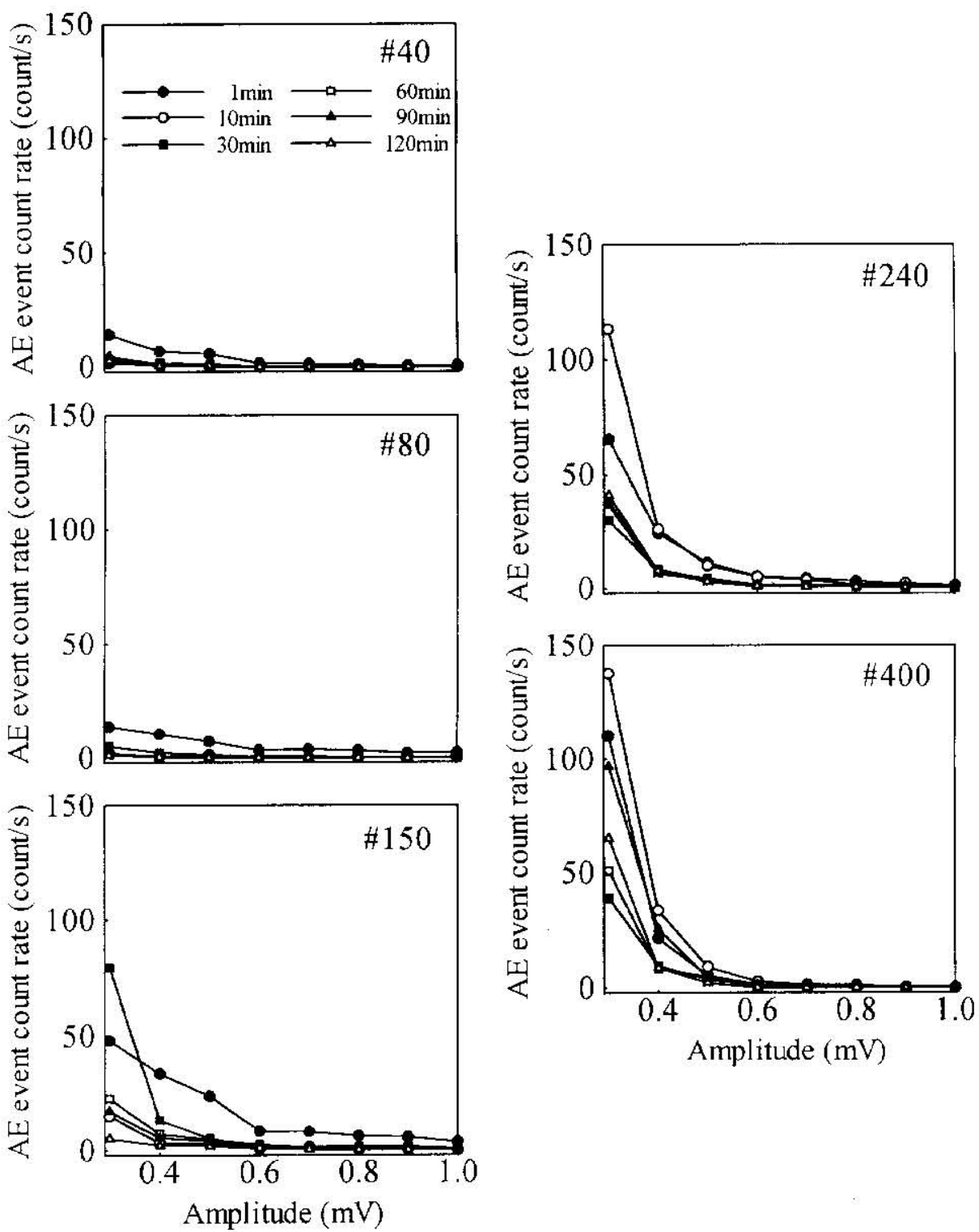

Fig. 6. Amplitude distributions of $\mathrm{AE}$ event count rate at each sanding time in sanding parallel to the grain. 


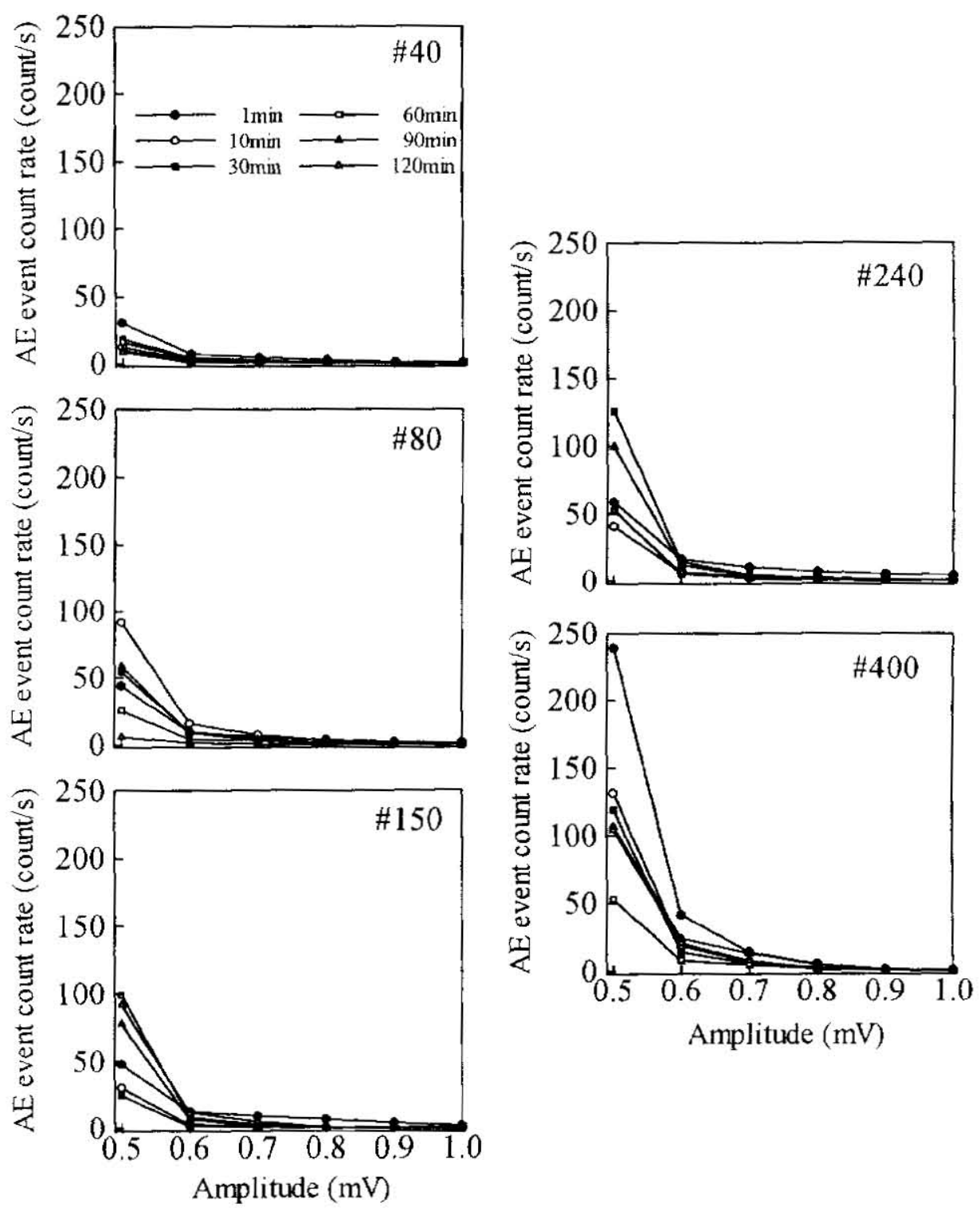

Fig. 7. Amplitude distributions of $\mathrm{AE}$ event count rate at each sanding time in sanding perpendicular to the grain. 


\section{Form of amplitude distribution of AE signal}

To evaluate the amplitude distributions of $\mathrm{AE}$ signal quantitatively, $m$-values were used by other researchers (Kishi, 1980; Ando et al., 1991). The $m$-value is obtained as the following equation:

$$
\log \mathrm{V}=\log k-m \log \mathrm{N}(\mathrm{V})
$$

where $\mathrm{V}$ is a given threshold voltage, $\mathrm{N}(\mathrm{V})$ is the number of $\Lambda \mathrm{E}$ cvent whose amplitude are equal or greater than $V, k$ and $m$ are constant. In this study, we tried to apply the $m$-value as a symbol of the form of amplitude distribution of AE signal. Figure 8 shows the examples of plotted $\log \mathrm{V}$ and $\log \mathrm{N}(\mathrm{V})$ to calculate $m$-value at each sanding time for grit size of 150 in sanding parallel to the grain. A linear relationship was established beiween $\log \mathrm{V}$ and $\log \mathrm{N}$ (V) and an application of eq. (1) was confifinted. The great $m$-value means the greater AE events for lower amplitude level, and small one means the greater $\mathrm{AE}$ events for higher amplitude level as well as for lower amplitude level.

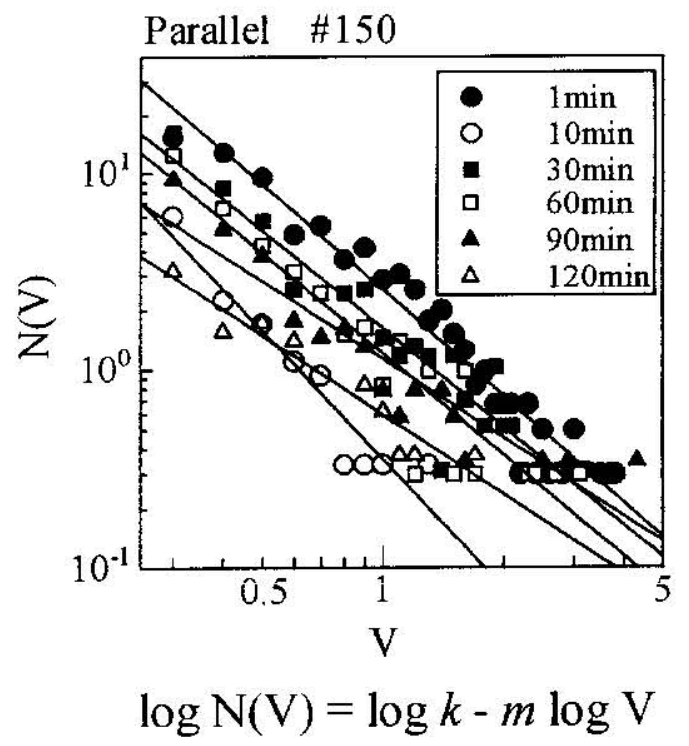

Fig. 8. Examples of calculate $m$-value in sanding parallel to the grain at the grit size of 150 . Legend: $N(\mathrm{~V})$ : AE event count rate (count/s), V: Thıreshold voltage $(\mathrm{mV})$.

Figure 9 shows the variations of the $m$-values with sanding time at each grit size in sanding parallel and perpendicular to the grain. Although the $m$-values vary widely and there seemed to be no great dilference with sanding time, they were greater for finer grit 

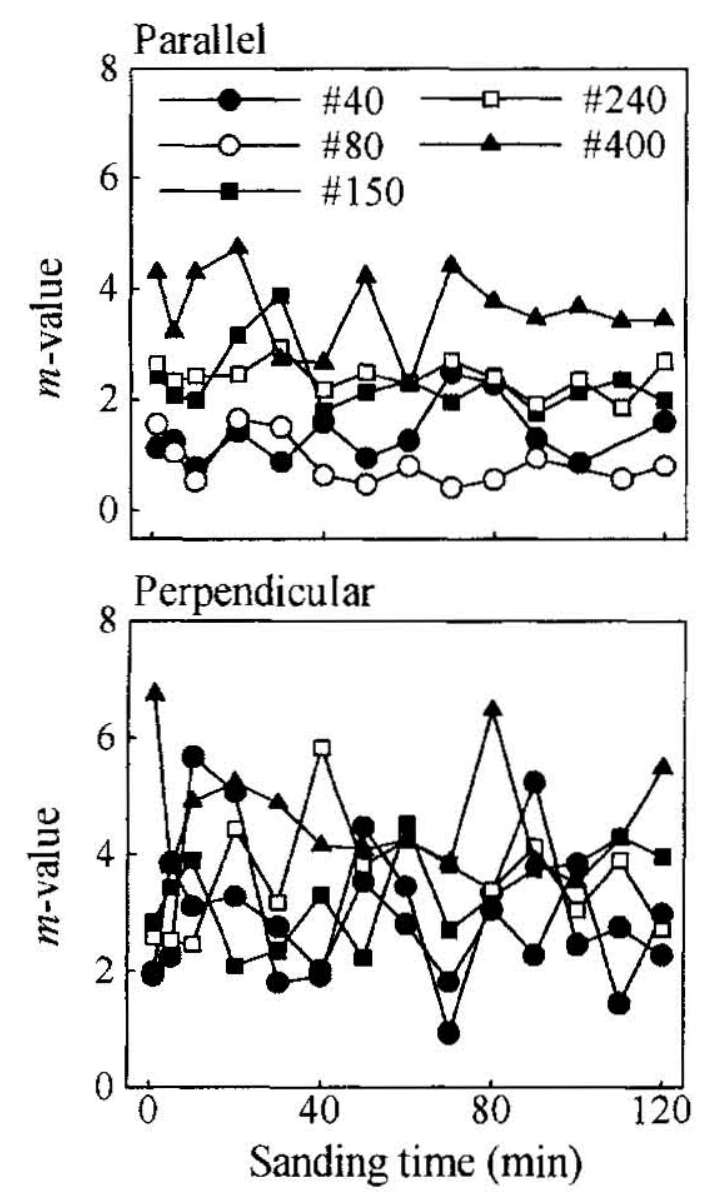

Fig. 9. Variations of $m$-valuc with sanding time for each grit size.

size. From these results, it was found that the $\mathrm{AE}$ events with low amplitude are greater for liner grit size and those with high amplitude are greater for coarser grit size in both sanding directions. It was suggested that the form of amplitude distribution of AE signal with sanding time does not change although the $\mathrm{AE}$ event count rate decrease with increasing sanding time.

\section{CONCLUSIONS}

In this study, the AE generated during sanding process with disc sanding machine were measured, and the effects of sanding time and grit size on both $\mathrm{AF}_{4}$ and sanding 
performance (stock removal rate, sanding resistance and roughness of sanded surface) in sanding parallel and perpendicular to the grain were examined.

The results obtained are summarized as follows,

(1) In both sanding directions, the $\mathrm{AE}$ event count rate decreased with increasing sanding time and this tendency was similar to the variation of stock removal rate with sanding time.

(2) The amplitude distribution of AE signal in this study showed a tendency that the $\mathrm{AF}$ event count rates were greater for lower threshold voltage, and they decreased with increasing threshold voltage. Although the $\mathrm{AE}$ event count rates were greater in lower threshold voltage for finer grit size, they decreased with increasing sanding time at each threshold voltage. Both the $\mathrm{AE}$ event count rate and the amplitude distribution of $\mathrm{AE}$ signal in sanding perpendicular to the grain were greater and wider than these values in sanding parallel to the grain, respectively.

(3) From the results of $m$-value, it was found that the AEs with low amplitude are greater for finer grit size and the AEs with high amplitude are greater for coarser grit size. It was suggested that the form of amplitude distribution of AE signal with sanding time does not change although the $\mathrm{AE}$ event count rate decrease with increasing sanding time.

\section{REFERENCES}

Ando, K., Sato, K. and Fushitani, M. 1991 Fracture Toughness and Acoustic emission characteristics of wood I. Effects of the location of a crack tip in an arıual ring, Mokuzai Gakkaishi, 37(12): 1129-1134

Kishi, T. 1980 Evaluation of Strength of Materials by Acoustic Emission (1), J. Soc. Mat. Sei., Japan, 29(323): $765-775$

Lemaster, R. L. and Jornfeld, D. A. 1993 Ths use of acoustic emission to monitor an abrasive machining process, Proceedings, 11 th International Wood Machining Seminar, Honne, pp. 231-246

Matsumoto, H. and Murase, Y. 1997 a Acoustic emission charactcristics in wood sanding H. Iffects of sanding pressure and sanding direction on acoustic ertission in belt sanding, Mokuzai Gakkaishi, 43(3): $280-284$

Malsumoto, H. and Murase, Y. $1997 \mathrm{~b}$ Acoustic cmission characteristics in wood sanding. Acoustic emission measurement in disc sanding, Proceedings, 13th International Wood Machining Seminar, Vancolver, pp. 353-361

Murase, Y., Ogawa, M. and Matsurnoto, H. 1995 Acoustic errission characteristics in wood sanding I. Effects of the grain sizes and the sanding times on acoustic emission in belt sanding, Mokuzai Gakkaishi, 41(7): 647-651 